\title{
Abstracts of the Contributed Papers to the International Conference on Emergency Health Care Development
}

\author{
Thursday, 17 August 1989 \\ Washington D.C. Metropolitan Area, 15-18 August 1989
}

\section{Forward}

Delegates from 78 countries who are involved with improving their local or national emergency services convened in the US Capital for this four day conference. Dr. James Mason, Assistant Secretary of the US Department of Health and Human Services welcomed the more than 600 participants. The Keynote address was delivered by Dr. Nancy Caroline, recent Senior Medical Officer with the African Medical and Research Foundation in Narobi, Kenya. She pointed out that the typical medical emergencies in the world are not cardiac, but diseases associated with poverty and hunger. Therefore, the solutions which apply advanced medical expertise and high technology are inappropriate and ineffective in many of the developing countries in which $76 \%$ of the human population of the earth reside. Trauma from motor vehicle accidents is becoming an increasingly important worldwide problem regardless of the national economy. However, in most parts of the world, hospitals and ambulances are scarce and the best hope for initial care is the bystander trained in first aid. The conference consisted of a series of discussions and workshops in which case studies, experiences, and lessons learned were shared. Lastly, a panel set forth global goals and solutions for the next decade in a CALL TO ACTION for WORLDWIDE EMERGENCY HEALTH CARE DEVELOPMENT IN THE 1990s.

The delegates to the International Conference on Emergency Health Care Development, out of concern for the increasing worldwide human and economic loss due to trauma and other medical emergencies, have reached the following understandings: 1) Emergency health care (EHC) consists of the timely provision of those preventive and curative interventions which can relieve pain or prevent disabilityand death; 2) Emergency health care is a basic need in all countries; 3) Injuries are responsible for increasing morbidity and mortality in countries of all levels of economic development, and frequently have a much moresevere effect on children and the working age population. Many injuries are preventable through health promotion and simple modifications in the home, school, and work environments; 4) Recent advances in health care organization and medical technology have made it possible to decrease significantly, the adverse effects of health emergencies; 5) When an injury or sudden illness occurs, the first response usually is provided by family members or bystanders. Community education can improve this response; 6 ) The majority of medical and traumatic illnesses typically present to the primary care system; and 7) When disasters occur, the first medical response is provided by local providers of routine emergency health care.

Based on these observations, we call for the following actions: 1) Health authorities at national, regional, and local levels should recognize EHC as an integral part of the primary health care system, and should ensure that their primary health care systems are capable of responding to emergencies; 2) Health authorities should make optimal use of local personnel by employing improved management techniques and training; 3) Health authorities should integrate into existing and future public educational activities curricula on injury prevention and response to emergencies and disasters; 4) The health care community should make its contribution to the International Decade for Natural Disaster Reduction by: a) strengthening local capabilities for responding to multiple casualty incidents using local personnel; b) ensuring that national committees for the decade are fully aware of the potential of EHC services in effectively reducing the impact of disasters; and c) adopting prevention and preparedness measures likely to reduce the number of casualties in a disaster; 5) World health authorities should collaborate in their efforts to bring to the attention of policy makers, the public health consequences of health emergencies, and the need to improve local urgent health 
response capabilities; 6) International health agencies and development organizations should collaborate in funding and assisting EHC development as a primary health care infrastructure improvement program; and 7) national and international disaster preparedness offices and agencies should work carefully with local emergency health care directors to coordinate plans for response to potential large scale events.

The major sponsors of the conference included the: US Public Health Service-Health Resources and Services Administration; US Department of Transportation-National Highway Traffic Administration; World Health Organization; and Pan American Health Organization. Collaborating organizations included the: United Nations Children's Fund; United Nations Disaster Relief Office; US AID, Office of Foreign Assistance; and Partners of the Americas.

\section{TRAINING/PUBLIC EDUCATION}

\begin{abstract}
Citizens Cardiopulmonary Resuscitation Training Programme in a Developing Country: The Malaysian Experience

M. Namazie Ibrahim $M D$

Citizens CPR Training Programme, Malaysian Medical Association (Perek), Perak, Malaysia

Coronary Heart Disease (CHD) has become the most common cause of death for Malaysians. This increase in mortality from $\mathrm{CHD}$ may be attributable, in part, to the increased affluence of the Malaysian Society occurred in traditional dietary habits, and to the increased incidence of smoking.

The value of laypersons performing CPR to resuscitate victims of heart attack has been demonstrated in several communities. This paper discusses the organization and management of the first Malaysian CPR training program for laypersons. It was organized by the Malaysian Medical Association and the Critical Care Section of the Malaysian Society of Anaesthesiologists and was co-sponsored by the Lions Club of Ipoh.
\end{abstract}

\section{Multi-step First Aid Training Educational System}

Thomas Braunsteiner MD, Milos Brix MD, P. Simko MD

Postgraduate Medical Institute, Bratislava, Czechoslovakia

Public First Aid Training in Czechoslovakia is the task of the Red Cross. We believe that cardiopulmonary resuscitation (CPR) is an organic part of First Aid. From of the point of view of didactics, we divide First Aid Training into: 1) life-saving measures (CPR, bleeding, shock); and 2) other first aid measures. Therefore, we developed a multistep educational system.

First, basic information about First Aid and healthy behaviors are taught to children in the kindergarten. From ages 6-10 yrs., school children learn the theory of CPR and gain basic knowledge in First Aid. From ages 11-14 yrs., practical CPR is taught. At the grammar school level, First Aid is part of the training of applicants for a driver's license. Short refresher courses are based on previous knowledge. First Aid training also is provided by employers with regards to employment specific problems.

Our aim is to train the whole public in at least the basic knowledge of CPR and First Aid.

\section{Training Ambulance Personnel in Costa Rica \\ Guillermo Rodriguez Gomez MD}

Several years ago, Costa Rican health authorities realized that the country's epidemiology had changed and that traumatic injuries had become the number three cause of death and disability. The Ministries of Health and Social Security devised plans for improving the health system's response to this newly important threat to the nation's health. It was recognized that one of the primary improvements to be made would have to come in the area of prehospital care and transportation of trauma victims. This presentation explains how Costa Rica mounted a training program for ambulance and rescue personnel. It was accomplished by using and coordinating the activities of several government ministries, the Costa Rican Red Cross, and an international, private, voluntary organization.

\section{Training System of Emergency Care Doctors in the USSR}

M. Vladislav $M D$

Emergency Health Care Department, Post-Graduate Medical Institute, Leningrad, USSR

A system for the continuous training of emergency care doctors has been introduced in the USSR. Emergency care chairs have been organized at the Medical Institutes. At the Post-Graduate Medical Institutes, there are chairs for post-graduate training of emergency care doctors. Post-graduate training consists of a three-year course at the chair of the emergency care. Following completion of this training, a certificate is given to the trained doctors and an increase in salary follows. Training must be repeated every five years or more frequently. This enables those trained in Emergency Medicine to pass the examinations required to reach the second, the first, and after that, the highest skill category within Emergency Medicine. Corresponding increases in salary accompany each successive level of accomplishment. This system has helped to stabilize medical staffs and improve the diagnostic and curative levels of the emergency health care in the USSR.

\section{Training Non-Hospital Personnel for Emergency Health Care} David Loudon $M D$

Medical Care Development International, Washington, DC, USA

This paper will present and evaluate some of the issues involved in training non-physician emergency health care personnel. It assumes a system in which patient care, in most cases, will be turned over to physician control in a definitive medical care setting. Some of the issues discussed also may apply to environments in which a lack of accessible hospital resources are likely to mandate that the non-hospital personnel will provide most of the emergency and definitive care outside of the hospital.

The discussion will begin with a brief review of the issue of training versus education for in-field health care workers. Then the discussion will focus on training within the broad context of organizational development. It will emphasize the need to assure that the training of clinical personnel also serves to strengthen the managerial capabilities of the health care delivery system. Techniques such as counterpart development, needs analysis, and interactive teaching methodolgies will be addressed. Examples from both mono-cultural and bi-cultural experiences will utilized.

\section{Training for Disaster Medicine}

S. W. A. Gunn

Vice President, Scientific Director, European Centre for Disaster Medicine

If disaster medicine is to become the serious discipline that we want it to be and it is likely to be, technical and scientific underpinning with appropriately trained persons is most essential. Therefore, I believe that in a Congress devoted to the subject, it might be useful to describe an idea for a disaster training center and to follow it through from its genesis to final completion and operational fulfillment. I refer to the European Centre for Disaster Medicine (CEMEC) established under to aegis of the Council of Europe, with permanent headquarters in the Republic of San Marino. Also, similar other training centers in the specialized fields of disaster, such as the Mediterranean Burns Club and the International Civil Defense Organization are described.

\section{MANAGEMENT}

International Donor Aid for EMS Development James E. Sarn

Agency for International Development, Cairo, Egypt

Currently, international donor agencies have focused the majority of their resources in international health towards the reduction of major causes of childhood morbidity and mortality particularly communicable diseases, malnutrition, and disaster relief efforts. With the increasing successes of key Child Survival interventions such as the Expanded Program of Immunizations and the Control of Diarrheal Diseases (ORT/ORS), accidents and chronic diseases are beginning to emerge as increasingly important issues for morbidity and mortality reduction. USAID experiences in Eygpt 
A quarterly

peer-reviewed

scientific journal

for physicians,

nurses, paramedics,

instructors, administrators

and researchers

\section{The official journal of:}

The National

Association of EMS

Physicians

The World Association for Emergency and

Disaster Medicine

\section{In Association with the Acute Care Foundation}

\section{JEMS \\ Journal of Emergency \\ Medical Services}

$J E M S$ is the monthly professional trade journal for the emergency medical services industry.

Whether patient care or administration is your focus, JEMS provides you with the news and information you need to stay current with the field.

For nearly ten years $J E M S$ has been serving the needs of EMTs, paramedics and their instructors and supervisors.

\section{Prehospital and Disaster Medicine}

Yes! Please enter my subscription to PDM for:

One year: $\square$ \$78 Institutional $\square$ \$48 Individual $\square$ \$35 Resident/In Training $\square$ \$35EMT, Pararaedic. RN Twa vear: $\square$ \$148 Institutional $\square$ \$88 Individual $\square$ \$65 Resident/In Training $\square$ \$65 EMT. Paramedic, RN NOTE: "Institutional" deffines multiple reader subscriptions, including libraties, haspitals. government agencies, and all pritate organizatians. Indicidual substriptions must be paid by indiciduals.

Name/Institution

Address

City State Zip

$\square$ Bill me $\square$ Charge my: $\square$ V'ISA $\square$ MasterCard Exp. Date

[ Payment Enclosed Card \#

For Canadian subscriptions, Signature Date add $\$ 10$

Occupation:

Make checks payable to: PDM. P.O. Box 1026, Solana Beach, CA 92075

ᄃ $\mathrm{Ph}$ sician

Vurse

$\square$ ENTT. Paramedi

Administrater:'Supv: Purch Agerı

Disaster Civil Defenst Planner

$\exists$ oither iPlease Spretit.
Employment Location

$\square$ Hospital

Fire Department

E Ambulane serice

$\square$ Regional State: Federal Agenc

Enduser:

I Diher.
Primary Specialty (if Physician)

[. Frmergence Modounc

Ef Critical Care

7 Tramuatolog

$\square$ Cartholug:

$\square$ oner
[- Prehospical Medical Durecier

\section{Prehospital and Disaster Medicine}

Yes! Please enter my subscription to PDM for:

One vear: $\square$ \$78 Institutional $\square$ \$48 Individual $\square$ \$35 Resident/In Training $\square$ \$35 EMT, Paramedic, RX Twoyear: $\square$ \$148 Institutional $\square$ \$88 Individual $\square$ \$65 Resident/In Training $\square$ \$65 EMT. Paramedic, RN NOTE: "Institutional" defines multiple reader subscriptions, including tibraries. hospitals. gocernment agencies, and all pricate arganizations. Indit idual subscriptions must be paid by indiciduals.

Vame/Institution

Address

Cinv State Zip

$\square$ Bill me $\square$ Charge my: $\square$ VISA $\square$ MasterCard Exp. Date

$\square$ Payment Enclosed Card \#

For Canadian subscriptions, Signature Date add $\$ 1$

. Hake checks payable to: PDM, P.O. Box 1026, Solana Beach. CA 92075

\begin{tabular}{|c|c|c|}
\hline Occupation: & Employment Location: & Primary Specialty (if Physician) \\
\hline I physician & $\square$ Hospilat & $\square$ Entergenes Medic ins \\
\hline I Nurse & EFire Department & $\Xi$ Cisitical Care \\
\hline$\Longrightarrow$ ExIT. Paramedic & Z Ambulance Servite & 7 Trammatologs \\
\hline$\exists$ Administrator Supl. Purch Agent & D Regional State Federal Agencs & [ Prebospital Medual Direcer \\
\hline$\square$ Disaster Civil Defense Planner & $\sqsubseteq$ Industr: & $=$ C.trdiology \\
\hline E Other & I Other & I Other \\
\hline
\end{tabular}

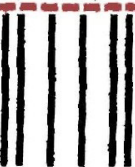

BUSINESS REPLY MAIL FIRST CLASS PERMIT NO. 6 SOLANA BEACH, CA

POSTAGE WILL BE PAID BY ADDRESSEE

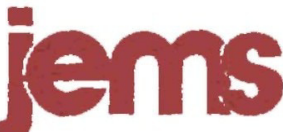

NO POSTAGE NECESSARY

IF MAILED

IN THE UNITED STATES

P.O. Box 27966

San Diego, CA 92128-9959

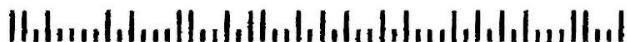




\section{BUSINESS REPLY MAIL}

FIRST CLASS PERMIT NO. 6 SOLANA BEACH, CA

POSTAGE WLLL BE PAID BY ADDRESSEE

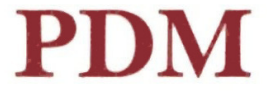

P.O. Box 1026

Solana Beach, CA 92075-9929

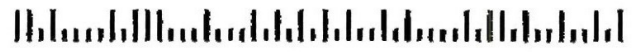

\section{NO POSTAGE NECESSARY \\ IF MAILED \\ INTHE UNITED STATES}

\section{BUSINESS REPLY MAIL \\ FIRST CLASS PERMIT NO. 6 SOLANA BEACH, CA}

POSTAGE, WILI. BE PAID BY ADDRFSSEE

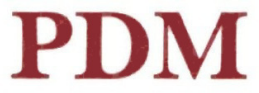

P.O. Box 1026

Solana Beach, CA 92075-9929

CALL FOR ABSTRACTS

The Sixth Annual Scientific Sessions and Meating of The National Association of EMS Physicians

\section{June 13-17, 1990}

\section{Houston, Texas}

- Presentations must involve EMS research

- Abstracts are límited to 250 words

- Accepted abstracts may be selected for either a poster session or for a 10 -minute slide presentation.

- Poster and slide presentations will be followed by a 5-minute question and answer session.

- Abstracts or manuscripts must not have appeared in a refereed journal prior to publication of the meeting abstracts in the July-September 1990 issue of Prehospital and Disaster Medicine and must not have been presented previously at a national meeting.

- Prehospital and Disaster Medicine is the official journal of the National Association of EMS Physicians and has the right of first refusal for all papers.

- Presenters will be asked to submit completed papers prior to presentation.

- Abstracts must be submitsed on the official abstract form which will be available int the January-March 1990 issue of Prehospital and Disaster Medicine. Call 800/228-367\% to receive official abstract form.

- Deadline: Abstracts must be received (not postmarked) by 5:00 PM April 2, 1990.

Submit abstracts to:

NAEMSP

230 McKee Place, Suite 500

Pittsburgh, PA 15213

\section{JEMS}

Journal of Emergency

Medical Services

\section{PRINT NAME}

TITLE

\section{ADDRESS}

\section{CITY}

STATE

Make checks payable to: Naws, P.O. Box 1026, Solana Beach, CA 92075.

Enclose payment and receive a 13th issue FREE!

$\square$ BILL ME occuration/POBITION

口A. Physicien

D. Nurse//nrt./Cocrd.

口 C. Admininsrator/Supervisor

D. Paramed./EMT-t/EMT-D

DE. EMT (Basic, 1s: Resp.)

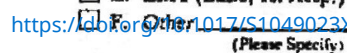

\section{PAYMENT ENGLOSED $\square$ CHARGE MY:}

\begin{tabular}{|c|c|c|}
\hline \multirow{4}{*}{ 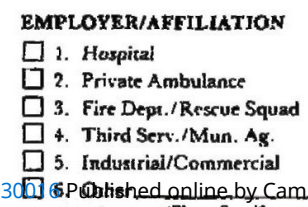 } & $\square$ MasterCard & Exp. Dare \\
\hline & Card & \\
\hline & Signature_ & Date \\
\hline & 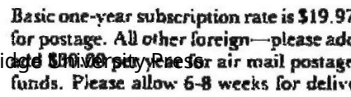 & $\begin{array}{r}0 \text { per year } \\
\text { il postage: } \\
\text { dd in C.S. } \\
\text { 39x-E7 }\end{array}$ \\
\hline
\end{tabular}




\title{
Subscription and Business Information
}

\author{
for the Readers of \\ Prehospital and Disaster Medicine
}

\section{SUBSCRIPTION PRICES}

\section{One-year}

(4 issues)

Two-year

(8 issues)

Institutional $\ldots \ldots \ldots \ldots \ldots \ldots \ldots \$ \ldots 78 \ldots \ldots \ldots$

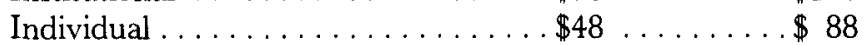

Resident/In Training ..........\$35 ......\$65

EMT/Paramedic/Nurse $\ldots \ldots \ldots \ldots 35 \ldots \ldots \ldots$

Note: "Institutional Subscribers" are defined as multiple reader subscribers and include public and private libraries, schools, hospitals and clinics; city, county, state, provincial and national government bureaus and departments; and all commercial and private institutions and organizations.

Individual subscriptions and all student-rate subscriptions must be in the name of, billed to, and paid by individuals. All studentrate requests must indicate training status and name of institution.

Send U.S. subscription orders to: Jems Publishing Company, PDM, P.O. Box 1026, Solana Beach, CA 92075; 619/481-1128; FAX: 619/481-2711.

\section{INTERNATIONAL SUBSCRIPTIONS}

Canadian subscribers add $\$ 10$ per year for postage and handling; Please include payment in U.S. funds.

For European subscriptions, contact: IOS, Van Diemenstraat 94, 1013 CN Amsterdam, Netherlands, FAX: + 3120226055.

For Japanese subscriptions, contact: IOS Japan Dept., Highway Developments Co. Ltd., 1st Golden Bldg., 8-2-9 Ginza, TokyoChuoku, Japan 104, FAX: +8135728672.

All other international subscription orders should be directed to: Jems Publishing Company, P.O. Box 1026, Solana Beach, CA 92075; telephone: 619/481-1128; FAX: 619/481-2711. All other international subscribers add $\$ 20$ per year.

\section{CHANGE OF ADDRESS \& MISSING ISSUES}

Please let your subscription representative know as soon as possible when you plan to move. We need four to six weeks advance notice for uninterrupted service. Send us your 1) current mailing label (with old address), 2) your new address and 3) effective date of change.

If you did not receive an issue, please let us know within three months of cover date.

If you have other questions about your subscription, please address them to: Customer Service, Jems Publishing Company, P.O. Box 1026, Solana Beach, CA 92075.

\section{EDITORIAL INFORMATION}

Please address all manuscript and editorial inquiries and comments to: Marvin L. Birnbaum, Editor, Prehospital and Disaster Medicine, 1552 University Ave., Rm. 434, Madison, WI 53706; 608/263-2069 or 608/263-7094; FAX: 608/263-2069.

\section{ASSOCIATION CONTACTS}

National Association of Emergency Medical Services Physicians, Executive and National Resource Center, 230 McKee Place, Suite 500, Pittsburgh, PA 15213; 1-800/228-3677.

World Association for Emergency and Disaster Medicine, Dr. Peter J.F. Baskett, Hon. Secretary/Treasurer, Dept. of Anaesthesia, Frenchay Hospital, Bristol BS 16 1LE, United Kingdom.

Acute Care Foundation, P.O. Box 280173, Tampa, FL, 33682; 813/988-0115.

\section{JEMS - Your Monthly Guide to EMS}

$J E M S$ was created nearly ten years ago with one goal in mind: to provide the top men and women of EMS with a monthly journal that would serve them as well as they serve their patients. Publisher Jim Page has been

involved in EMS for over 30 years as a rescuer, administrator, attorney, lecturer and writer. He designed a journal that would feature lively writing and graphics to match the dynamic growth of the EMS industry.

\section{You'll find in JEMS:}

- Monthly case studies of actual prehospital calls for CEU credit for EMTs and paramedics.

- "Tricks of the Trade" to enhance your patient care skills.

- Up-to-date news on the people and events that affect your job.

- A yearly salary of all EMS personnel-how does your department compare?
- Comprehensive information resources on all aspects of EMS

- Annual buyer's guide with the most complete and accurate listing of products, services, manufacturers and distributors.

- Essays and opinion on the issues you face everyday on the street, in the classroom and in your organization.
- Photographs and artwork that explain and entertain.

- Interpretive reports on the current research.

- Regular columns on pediatric care, EKG interpretation, clinical questions and answers, new books and new products.

- Regular columns on quality assurance, instructor training, the public/private interface and legal issues.

To subscribe, please fill out the attached card.

If missing, please send a check for $\$ 19.97$ for a year's subscription (12 issues) to:

JEMS, P.O. Box 1026, Solana Beach, CA 92075 


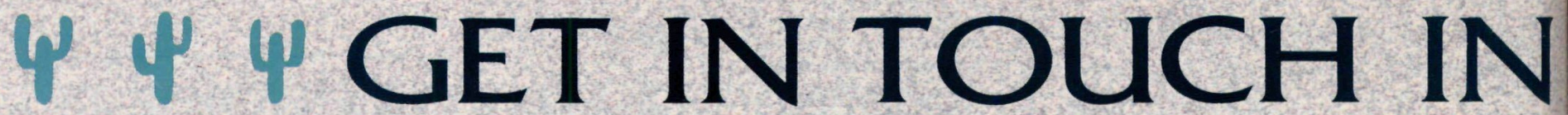

EMS TODAY is more than a national conference. . for many it's a time of renewal. A time to visit with colleagues and friends in an atmosphere of enthusiasm, innovation and contemplation. Inspirational leaders remind you of the values that originally attracted you to EMS, and challenge you to refresh your dedication to the battle.

This year EMS TODAY visits the perfect place for renewal-the sun and the beauty of the Arizona desert. Join over 1,000 of the nation's most interested-and interesting-EMS professionals in Tucson to learn together, share experiences, and rejuvenate the spirit.

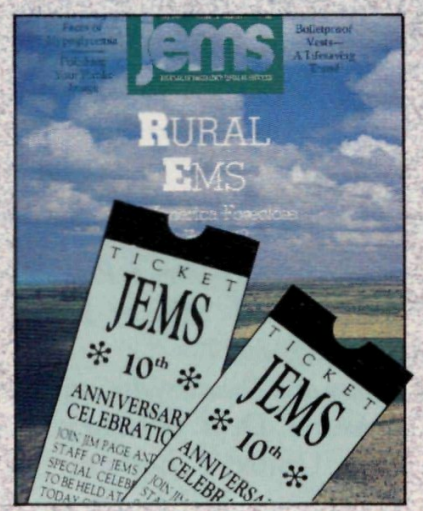

JEMS, the Journal of Emergency Medical Services, sponsors EMS TODAY and will celebrate its 10 th anniversary with its February, 1990 issue. Join Jim Page and the staff of JEMS at a special 10th Anniversary party at the conference.

\section{Educational Sessions for All Interests}

You can find just the session you're looking for in one of the five tracks the conference features:

1) Clinical, 2) Administrative, 3) Instructor, 4) Medical Direction and Leadership, and 5) new this year, Fire/Rescue. In addition, there will be preconference workshops that concentrate on specific issues and skills, and four general sessions that bring together the entire audience.

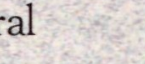

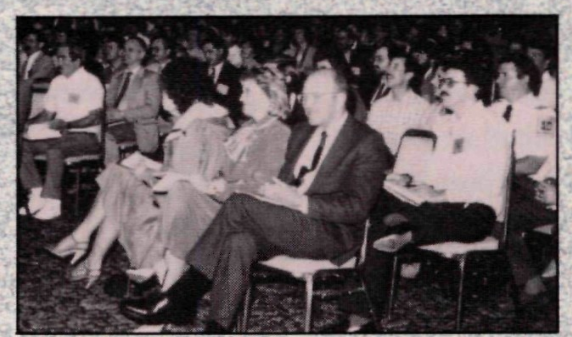

Join over 1,000 of your colleagues for education and inspiration.

You can depend on EMS TODAY to confront controversy, explore new angles in patient care, promote professionalism in management and education and provide practical skills and knowledge you can take home with you. We designed the program to promote interaction between all the people who have a stake in making prehospital care work.

How else can you change attitudes and create real teamwork?

\section{New Products and Services Introduced}

You'll find the largest exhibit hall in the history of our conference in Tucson, with 150 manufacturers and distributors representing every kind of product and service. Each evening we sponsor a "curbstone consultation" in the hall to bring together faculty and participants to continue the day's

dialogue in a more relaxed setting. 


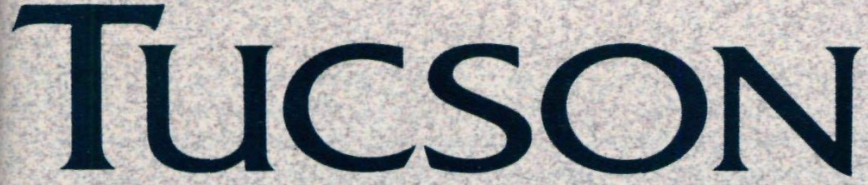

\section{The Winter's Sunny Oasis}

Tucson is easy and inexpensive to fly to and the EMS folks in Arizona are eager to show you their beautiful state. The Grand Canyon, beautiful mountains, dazzling desert colors, southwest art and cuisine, golf, tennis, and the warm sun all await.

Get in touch in Tucson, with the best part of EMS ... and the best part of you.
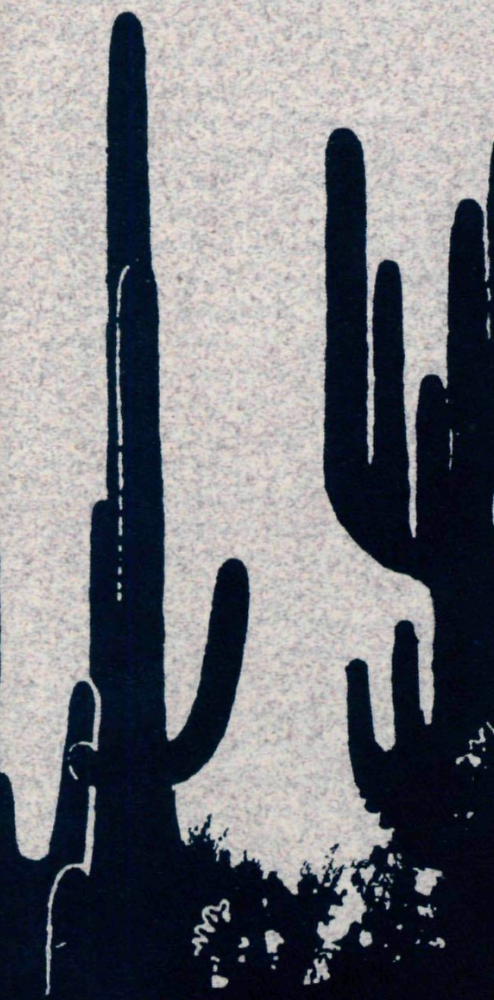

\section{$t$}

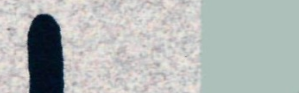

\section{CONFERENCE}

AND

February 14-17, 1990

TUCSON CONVENTION CENTER
TUCSON, ARIZONA

The National Conference for Paramedics, Nurses, Physicians, Instructors, Supervisors, and Administrators

Presented by Jems, the Journal of Emergency

Medical Services and

The Conference Corporation

Please send me an

EMS TODAY registration packet!

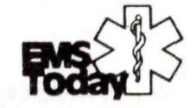

Name

Company

Address

Tucson in

February is

winter's sunny

oasis. Enjoy

golf, tennis,

hiking, and

shopping in

southwest stvle.
City__ State

Zip Phone

Mail to: The Conference Corporation

P.O. Box 805

Solana Beach, CA 92075 619/481-5267 
indicate that relatively low-cost interventions in the improvements of EMS training, transportation, communications, and planning can have a significant impact on service delivery improvements. Participation in emergency health services development and accident prevention increasingly should provide donors with major opportunities to introduce cost-effective preventative and curative services into health care services.

An Investigation of the Job Characteristics of Emergency Medical Careers and Factors Influencing Job Satisfaction

Stephen R. Wirth, M.S., REMT-P

Erie, Pennsylvania, USA

In the midst of a general shortage of health care workers in many countries worldwide, effective recruitment and retention of a qualified and satisfied work force is a critical issue. This study examines factors in the structure or design of the work of emergency medical technicians and paramedics that can create conditions necessary for high levels of work motivation, performance, and overall job satisfaction.

A modified Job Diagnostic Survey was administered to a cross-section of $\mathbf{1 0 2}$ paid and volunteer emergency medical personnel. Following the job characteristics theory developed by Hackman and Oldham, the relationships among measured job characteristics, experienced psychological states, and of overall job satisfaction were examined.

Significant positive relationships $(p<.05)$ exist between the job characteristic variables (such as task significance, autonomy, and job feedback) and job satisfaction. The number of years working in the EMS field (job longevity) did not have a significant relationship to job satisfaction. Volunteer EMS personnel experienced higher levels of job satisfaction than did paid providers. These results indicate that the EMTs and paramedics perform complex jobs that have high levels of the characteristics that cause internal work motivation. Methods to increase the amount of the core job characteristic; to improve overall job satisfaction are discussed.

\section{Volunteer EMS Personnel}

\section{Paul B. Anderson}

Chief, Idaho EMS System, Idaho, USA

In rural and frontier areas, most EMS personnel are volunteers. For example, in the State of Idaho, USA, over $90 \%$ of the EMS personnel are volunteers. These volunteers staff more than 200 local EMS units.

Typically, volunteer EMS personnel are very highly motivated and dedicated. However, EMS crews that primarily are comprised of volunteers need to maintain their livelihood in some manner other that from EMS activities. Therefore, EMS programs must be designed to permit this to occur. For example, in order that volunteers do not have to travel long distances to participate in the required training, EMS training programs should be taken to rural communities. The volunteer's time is valuable and there is a limit to the expense that can be incurred on the part of the individual, volunteer EMTs. There is a need to develop training programs that can reach volunteers in widely dispersed locations. Examples include the use of teleconferencing and mobile training units. Also, the use of new technology such as interactive laser video discs could be explored. Such interactive programs could provide simulations which could substitute partially for the paucity of exposure of these personnel to critical patient situations.

Also, technology can be used to reduce some of the burdens associated with being on call. For example, equipping such personnel with portable radios allows on-call personnel to have some freedom of movement within the local community. However, many rural areas do not yet have an EMS radio system in place to reach such portable radios. For some rural areas and most frontier areas, this capability awaits the implementation of satellite communication links for EMS.

Rural volunteer EMS personnel need to know they are appreciated by the community they serve. Thus, there is a need for EMS systems to initiate recognition programs to ensure the volunteer personnel receive such recognition.

A number of factors may affect retention rates. These factors include: 1) Liability coverage; 2) Workmans compensation; 3) Run volume-Too much call time for some personnel may lead to burnout and too little exposure to actual emergencies may lead to rustout; 4) Reimbursement for personal expenses; and 5) Assist the EMTs to cope with job-related stress. These and other factors that pertain to volunteer EMS crews will be addressed.

Organization, Administration, and Management of the World's Largest Geographic Prehospital Care System

Fred Bates, Neil Leard, Charles Sun MD

British Columbia Ambulance Service, Emergency Health Service, Canada

British Columbia is a western Canadian province with a single, prehospital care system which covers a geographic area greater than California, Oregon, and Washington combined. The Service has been operational for 25 years. It provides prehospital care and inter-hospital transports for all citizens and hospitals within the Province by land, sea, and air. The British Columbia Ambulance Service is comprised of 359 ambulances located in 180 communities. Annually, 700 full-time and 2,300 part-time employees transport approximately 270,000 patients. The attendants are trained to the Emergency Medical Assistant I, II, and III levels. The Emergency Medical Assistant III level attendants provide advanced life support care for both adults and children. Approximately 1,000 neonatal or pediatric patients are transported by the Infant Transport Team by air and ground annually. The air evacuation program conveyed 6,000 patients last year: 3,000 by prop plane, 2,000 by jet, and 1,000 by helicopter. All of the calls are dispatched using only three dispatch centers located in the Province. The total annual operating budget for the Provincial system is appoximately $\$ 66$ million.

\section{Recent Advances in Ambulance Siting}

Charles ReVelle PhD, Vladimir Marianov

Department of Geography, Johns Hopkins University, Baltimore, Maryland, USA and Catholic University of Chile

The deployment of ambulances in a large metropolitan area has been a subject of analysis for almost two decades. Mathematical representations have evolved from the early deterministic forms to probabilistic forms. The first models were designed to cover populations and calls by initial positioning of ambulances within a time or distance standard for each demand area. A second generation of models sought to position additional or backup servers for each demand area as a means to increase the probability that service would be available within the time to place ambulances at positions that will ensure that each demand area has an ambulance available within the time standard with a stated level of reliability. The development of these ambulance siting models is reviewed with an emphasis on explanation of objectives rather than mathematics. Data and software needs to implement these models are detailed.

\section{DISASTER PREPAREDNESS}

\section{Disasters and EMS Delivery in the Next Century}

E. L. Quarantelli

Director, Disaster Research Center, University of Delaware, Newark, Delaware, USA On the basis of our extensive past and ongoing field research on the delivery of emergency medical services in natural and technological disasters, we project what the situation probably will be like as we move into the 21 st century. Our themes are three:

1) Insofar as the delivery of EMS in future disasters is concerned, the future will be worse than the present. There is every reason to think that there will be both quantitatively and qualitatively more demanding disasters in the decades to come. Also, there is the paradox that continuing improvements in medical technologies increasingly will not lend themselves well to use in the field in future disasters.

2) There will be a need to innovate along at least two lines. First, the use of new technological possibilities in the medical areas have to be explored. Second, social scientists need to define the different kinds of institutional arrangements for providing disaster EMS which must be evolved.

3) The future world will not be homogenous. Therefore, there will be a need to examine both the cross-societal differences between the uses and capabilities of medical technology and in relative vulnerabilities to disasters. Therefore, a major goal must be the development of alternative models of EMS systems which can be used in different societies to handle the more numerous and more complicated disasters of the future. The likelihood that those societies which will be most vulnerable to disasters are 
those that are more likely to have poorer medical facilities. Technologies will constitute a significant problem for the world community.

\section{Sliding Scale in Emergency Medical System}

\section{Roel Huijsman-Rubingh MD, DPH}

Department of the Chief Medical Officer of Health, The Netherlands

After World War II, the Netherlands government set up an organization for protection of the population under the name Organisatie Bescherming Bevolking (Civil Defense), better known by the abbreviation, BB. Its purpose was to provide help for the populations in disasters under exceptional conditions. The trend towards reduction of expenditures led the government, in 1980, to abolish the BB and to make use of a sliding scale. This is a staged-growth model and as the starting point is organized to meet the everyday, non-disaster-related situation.

As required by an actual disaster situation, the organization can expand in to a wider range of activities without mandating any fundamental changes in the existing organizations which have clearly defined expertise and command structures. This growth model consists of five stages:

Stage 0: A Major Accident-Medical help takes place according to the normal procedures.

Stage 0 plus: An Exceptional Occurence-Two or more on-call help services are activated. Communications and coor

dinated action between these services is necessary.

Stage 1: A Disaster (defined in Article 1 of the disaster law)-The local mayor installs a disaster staff and a scene-of-

disaster command

Stage 2: A Major Disaster-The mayor decides to install a regional command.

Stage 3: A Disaster under Exceptional Conditions-At this stage, help is available from mobile units and ambulance

teams of the Korps Militaire Colonnes (KMC), e.g. a military organization. The basic health services, the central post for ambulance transport, and the ambulance services are important elements in the early stages. At later stages, the Netherlands Red Cross and the KMC take the lead.

\section{Prodromal Sentinel Markers in Industrial Disasters}

\section{E.D. Richter MD, MPH, P.Deutsch, MPH, Y. Adler MD}

Head Unit for Occupational and Environmental Medicine, Hebrew University School of Health and Community Medicine, Jerusalem, Israel

Everday routine occupational health and safety programs can be programmed to identify and treat prodromal sentinel markers for industrial disasters. A sentinel marker is a pre-disaster warning sign of impending failure in safety program; lack of spontaneous access to top management; failure to accept responsibility for sub-contractors; the absence of written disaster plans and drills of the emergency responses in the factory and the adjacent community; non-investigation of prodromal leaks, exposures spills, or injuries; punishment of troublesome individuals reporting such prodromal events; non-use or misuse of data on illness, injury, and absenteeism; and sub-optimal work conditions and supervision of shift workers. Information sentinel markers include: absence of worker and community right-to-know programs; non-use of data on earlier mishaps from similar technologies; and failure to provide toxicologic data in hospitals in the predisaster phase. Technological sentinel markers are: absence of fail-safe controls, interlocks, and automated alarm systems driven by real-time monitoring. Transportation sentinel markers include sub-optimal vehicle standards and drink, drugs, and/or fatique in drivers. Preventive programs based on identification of all sentinel markers are suggested to be more effective than selective action based on risk assessment analysis.

\section{Emergency Preparedness in Relation to Natural Disasters in Africa Sandro Calvani $M D$, Ruth Fellows WHO Panafrican Centre for Emergency Preparedness}

Prioritization of disasters specific to Africa has shown the primary causes to be drought and famine. Second in importance are war and civil strife, and third being refugees and displaced persons. Floods, cyclones, and seismic disasters rank fourth, and fifth are epidemics. Disasters have become the order of the day. An increased vulnerability to climatic variations, deforestation, desertification, over-population, pest infestations, rapid urbanizations, political disturbances, and economic decline are some of the major issues which increasingly are taking a toll of the people of Africa. The cumulative effects of these problems, compounded by the massive disasters witnessed in the 1980 s, have left some countries crippled by food shortages, mounting food import bills, an increased dependence on food aid, and coping with large refugee populations.

The effects of disasters, elevated mortality rates, disabilities, increased disease entities, and the displacement of millions of people tend to be significantly intensified in the developing world. Unfortunately, despite the developing gravity of increasing morbidity and mortality, when compared with the widespread nutritional deficits, invariably health needs are given a second place of importance particularly in relation to disaster preparedness contingency planning. Yet, disasters result in the disruption in the provision of basic health services, may increase food shortages, interrupts disease surveillance and control programs, and may affect the infrastructure of health facilities. Clearly, following the occurence of a sudden disaster, most injuries occur during the initial impact. Thus, the greatest need for emergency care occurs within the first 48 hours of the event. Hence, the burden of organizing and delivering transport, first aid, medical care, and supplies falls on the affected country. Therefore, it is of prime importance that during the preparedness phase, an important part of contingency planning must include an inventory of all of the resources available. All areas in which there is a shortage of health and food supplies must be identified, and the potential health impacts which are most likely to occur in light of each type of disaster must be considered. Without an operational infrastructure, a chaotic situation is made worse, and incountry resources cannot be distributed appropriately to the affected area. This is likely to result in significant increases in the loss of human lives. Therefore, in order to develop effective coping mechanisms, both the countries exposed to potential disasters and personnel involved in the management of the disaster responses must learn strategies for mitigation and implementation. The resulting actions will involve the identification of hazards, mitigation efforts, disaster planning, disaster legislation, and the development of disaster warning systems.

With any disaster-preparedness program, public awareness, information dissemination, and training of personnel constitute the fundamental ingredients for success. It becomes critical that training occurs at every strata of society from policy makers to field workers who are associated with disaster-preparedness and responses. Given the scarcity of resources available to the developing world, comprehensive training for disaster preparedness and intervention becomes essential in order to reduce human and property costs of disasters, and to diminish the wastage, delay, and misoriented development undertaken during the recovery phase.

\section{EMS and Refugees: An Epidemiological Disaster}

Michael J. Toole MD, DTMËH

International Health Program Office, Centers for Disease Control, Atlanta, Georgia, USA

Displaced populations in the developing world pose a tremendous challenge to the international health community analogous to the emergency room in clinical medicine. More than 14 million refugees currently are receiving assistance, mostly in developing countries such as Somalia, Ethiopia, Sudan, Pakistan, Thailand, and Honduras. Mortality rates during the early post-influx phase have been reported between 1030 times the expected mortality rates (based on host country rates). In addition to refugees seeking asylum in neighboring countries, an estimated 1420 million people are displaced within their own countries (e.g., Sudan, Mozambique, El Salvador, Sri Lanka). The most commonly reported causes of death are measles, diarrhea, acute respiratory infections, and malaria. In many instances, these processes are exacerbated by malnutrition. Unusual nutritional deficiency syndromes (e.g., scurvy and xerophthalmia) are being reported from these populations. Access by relief workers to these populations often is very difficult. In general, the priority relief programs for displaced populations should aim to prevent high mortality. They must include adequate food rations, measles immunization, clean water and sanitations, epidemiologic surveillance, and diarrheal disease control programs. 
Principles of the Organization of Medical Action in Case of a Disaster in France

Phillippe Hrouda MD, Pierre Huguenard $M D$

Emergency Medical Service and Disaster Medicine Support Detachment, Henri Mondor University Hospital, Creteil, France

Following the introduction in 1981 in France of University teaching in Disaster Medicine and the application of the European Community Directive No. 82-501 EEC (the Seveso Directive), French authorities were led to draw up new Relief Organization Plans aimed principally at technological developments and the hazards that they entail.

Thus, a recent law on the organization of Civil Safety and prevention of major hazards establishes new relief organization plans which are intended to assure specific and progressive responses to numerous, largescale accident or disaster situations. Following passage of the law, the establishment of medical action within the relief chain has been possible. Thus, disaster doctors can carry out their duties by taking their statutorily defined place at the assigned different levels in the relief chains. That medical chain was applied by the French government in providing assistance in Armenia following the earthquake of December 1988.

\section{A Ten-Year Experience of a French Disaster Medicine Support Detach-} ment

Phillippe Hrouda MD, Pierre Huguenard MD

Emergency Medical Service and Disaster Medicine Support Detachment, Henri Mondor University Hospital, Creteil, France

The intervention, at the scene of a disaster by Medical Support Detachments made up of civilian hospital staff, is a recent phenomenon principally linked in France to the standardization of prehospital medical care and to the development of university teaching in Disaster Medicine. The manpower consists of intensive care physicians and nurses, both especially trained in Disaster Medicine. Equipment which could be used in every possible kind of situation, and which facilitates the triage of numerous casualties, assists in the ease of their identification, and documents the medical care provided before their evacuation has been packaged. In mass casualty situsations, these equipments and supplies are used to reinforce the basic components of conventional means of relief which can be provided by Civil Safety Units, Fire Brigades, or even military means in peacetime. At present, our hospital detachment is the one with the most experience. It has been used in governmental assistance in: Algeria in October 1980 (earthquake in El Asnam); Mexico in September 1985 (earthquake in Mexico DC); Colombia, November 1985 (mud flow in Armero); Salvador during October 1986 (earthquake in San Salvador); and Armenia in December 1988 (earthquake in Leninakan).

\section{Hospital Plan for Disaster Cases: Juarez de Mexico Hospital}

Carlos Rojas, $M D$

On 19 September 1985 at $0718 \mathrm{H}$ local time, one of worlds largest cities with 18 million inhabitant was shaken by an earthquake that caused a large number of deaths and incalculable losses. Numerous buildings were damaged and 5728 buildings were seriosly affected. The majority of buildings seriously damaged were between 6 and 15 stories high. In the metropolitan area, the health care sector immediately lost the use of 3467 rooms at levels II and III. The Juarez de Mexico Hospital, one of the country's oldest (founded in 1847) also was destroyed. Its hospitalization unit was 12 stories high, was constructed in 1970, and contained 536 patient rooms. As a result of the tragedy, 561 bodies were recovered from the ruins. Of these 118 never were identified. Of the total dead, 266 were hospital workers of which 44 were medical specialists.

Presently, a hospital plan for internal and external disasters exists. This plan has been tested periodically with mock disasters and its effectiveness was confirmed during the quake of 25 April 1989. The Surgical Ambulance Linit with 20 beds and four operating rooms was evacuated quickly. Continued attention was provided to anesthetized patients. This increased the operating capacity of the Emergency Services to care for victims of the quake. The plan was evaluated, shortcomings were identified, and solutions to these shortcomings are being offered.

\section{COMPARATIVE COUNTRY STUDIES}

Role of Voluntary Agencies in Development of Accident \& Emergency in a Developing Country: A Challenge and a Lesson

Dr. Gautam Sen MS, FRCS

Vice President, Association for Trauma Care of India

This paper describes the current status of Accident and Emergency (A\&E) organization in India. It reviews: 1) the magnitude of the problem; 2) the major factors which contribute to the high rate of accidents; and 3) the causes for high rates of mortality and morbidity. It highlights the importance of multidisciplinary efforts in the development of a systems approach towards developing a Comprehensive Accident and Emergency Medical System in rural sectors, at the district levels, and in the urban megacities in the state. Also, it describes mechanisms by which the A\&E services are integrated with the National Disaster Medical Response System.

The paper defines, in practical terms, the mechanisms by which a nucleus of Prehospital Services was developed by a Voluntary Agency: The Association for Trauma Care of India in the city of Bombay. The Project was named the Golden Hour Project. It discusses how this Project was conceived and how a multidisciplinary effort was utilized. The private and public sectors joined hands and with the cooperation of the Federal authorities, the basic infrastructure was established. In addition, the paper describes its current status and problems, and how it has provided a nucleus and impetus for further development of Prehospital Services in the state in particular, and the development of A\&E services organizations in general.

The principal lesson to be gleened from this Project is that, provided there is individual initiative and commitment, even in a developing country with resource constraints, A\&E services can be improved significantly with multidisciplinary efforts by both Federal and non-Federal authorities.

\section{Emergency Medical Service in the Kingdom of Saudi Arabia \\ Abdulla Mohammed Al-Hazzaa}

Director General for Ambulance and Relief, Saudi Red Crescent Society, Saudi Arabia

We are living in an age in which many factors are responsible for accidents which result in many injured victims. In order to achieve health and safety for the members of the community, it is a necessity for every country to establish a comprehensive and fully integrated system for the Emergency Medical Services (EMS). The Kingdom of Saudi Arabia is one of the countries that has experienced rapid development and unique evolution. Suddenly, car accidents constitute the main cause for mortality and disability. The mortality rate from accidents in the kingdom is one of the highest in the World. Therefore, in response to this finding, in 1963, the Saudi government attempted to increase the effectiveness of the comprehensive emergency medical services organization by placing it administratively in the Ministry of Health supported by the medical services of the military, educational agencies, and the services of the private medical sector. All of these agencies are supported substantially by the government. Prehospital EMS activities are centered in the Saudi Red Crescent Society which is supported by the Emergency sections of the government hospitals and Civil Defense. Since its establishment, the Saudi Red Crescent Society has attempted to define its role and improve its services through the development of the basic elements for EMS: 1) Manpower; 2) Transportation; 3) Communications; 4) Supplies and Equipment; and 5). Construction.

The Saudi Red Crescent Society started to increase and expand its services in the towns, villages, and highways so that in 1989, it is comprised of a total of 140 Ambulance Centres. In order to examine the experiences in the field of EMS of some of the developed countries, it was decided to study some of their systems and experiences. Through the Saudi-United States Joint Commission on Economic Development (JECOR), a specialized American team visited the kingdom to study the EMS system in order to evaluate the services rendered and to make recommendations and suggestions for further development. In 1983, an agreement for cooperation in the field of EMS under the umbrella of the JECOR was signed. In 1985 , the specialized working team, which included experts in the various components of EMS systems, arrived in the Kingdom. 


\section{DOES YOUR COLLAR MEASURE UP TO STIFNECK? DOES I T H AVE AN...}

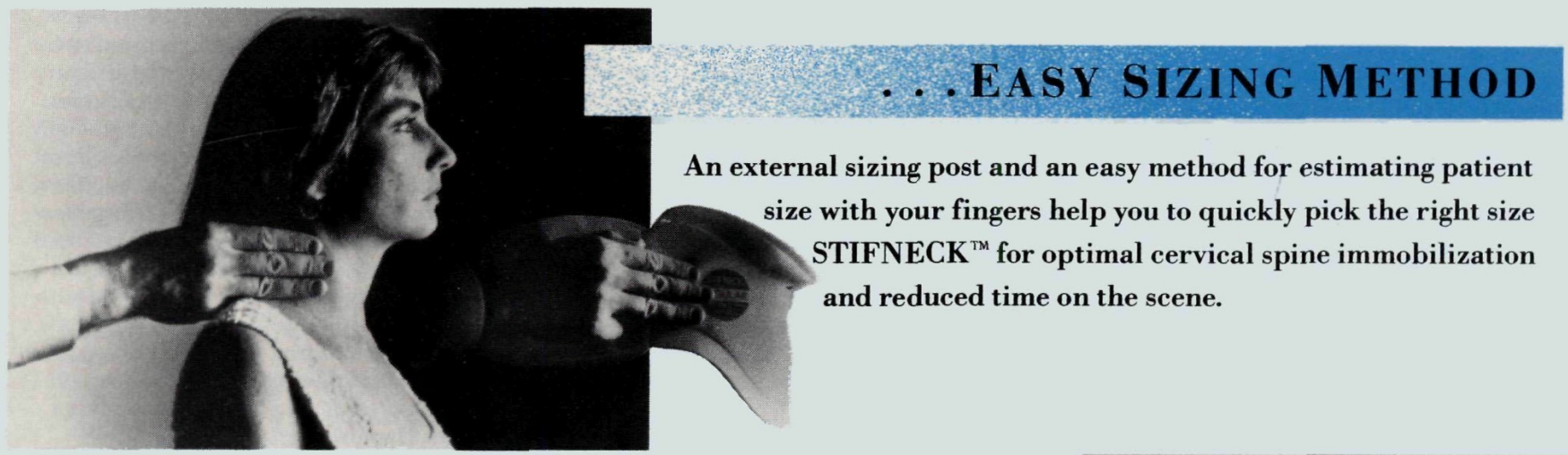

\section{ANSWER FOR NO-NECKS}

The recently introduced NO-NECK ${ }^{\mathrm{TM}}$ size enables you to properly fit those patients with extremely short necks who used to be a real problem. STIFNECK's broad range of fit has been expanded even further by the addition of a BABY NO-NECK ${ }^{\mathrm{TM}}$ model designed to fit children aged 1 to 4 years.
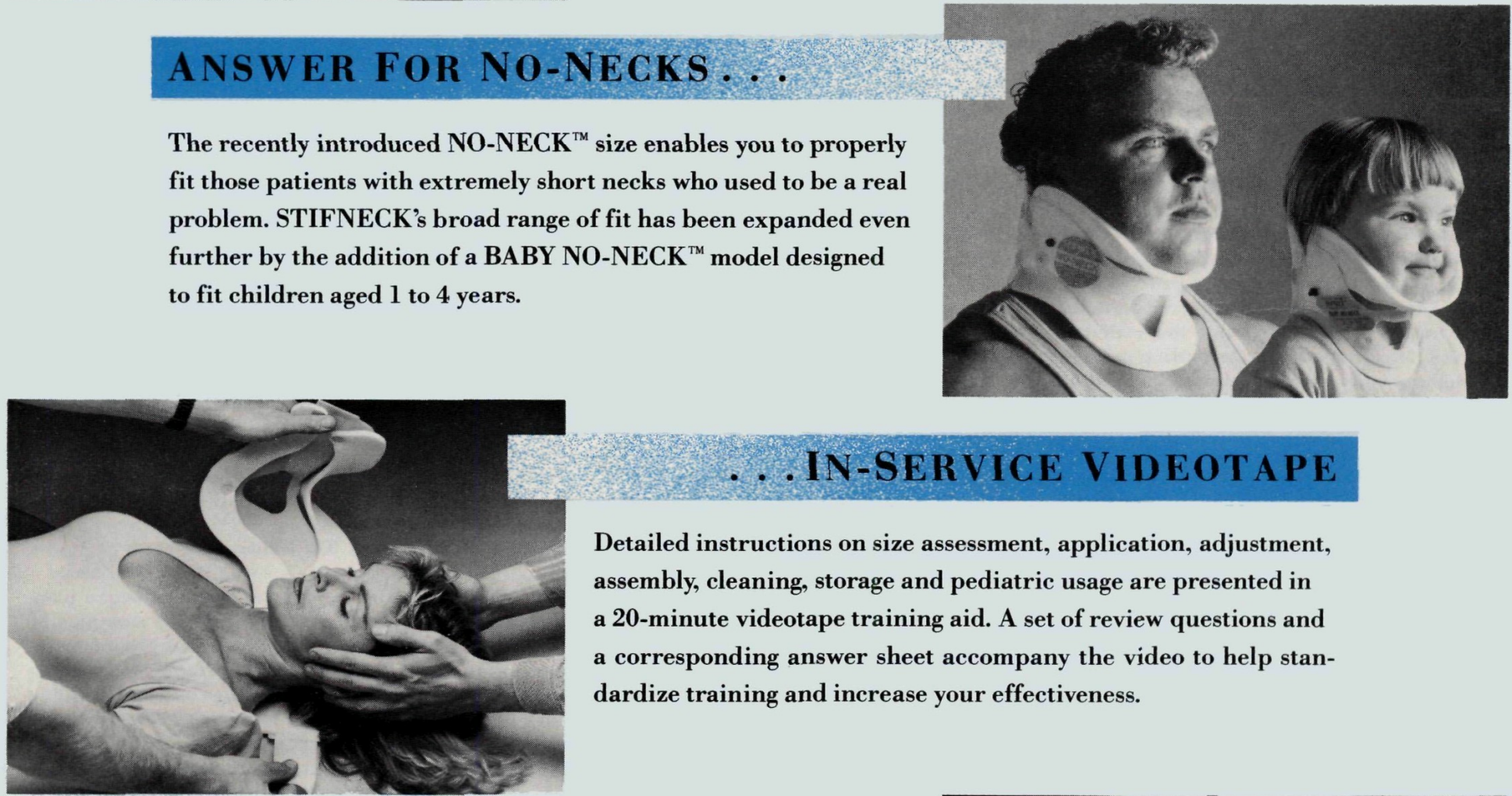

\section{. . IN-SERVICE VIDEOTAPE}

Detailed instructions on size assessment, application, adjustment, assembly, cleaning, storage and pediatric usage are presented in a 20-minute videotape training aid. A set of review questions and a corresponding answer sheet accompany the video to help standardize training and increase your effectiveness.

X-RAY DOCUMENTATION PACKET

You can feel confident when using STIFNECK ${ }^{\mathrm{TM}}$ as a series of radiographic studies have shown the collar to provide safe and effective immobilization of the cervical spine in the neutral position. In addition, comparative $\mathrm{X}$-ray studies have shown STIF NECK ${ }^{\mathrm{TM}}$ to provide a higher degree of immobilization than other cervical collars tested.

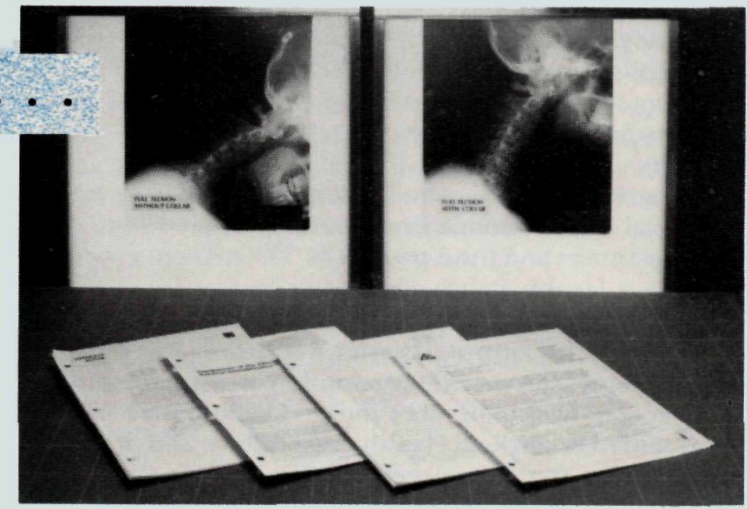

\section{DON'T ACCEPT SUBSTITUTES. DEMAND THE BEST. ..STIFNECK.}


Training of personnel received the greatest attention. Training programs were directed at all levels starting with those persons working in the ambulance field. Substantial attention was directed at Public Health education. Six training centers were established in different regions.

Saudi Red Crescent activities played a prominent role in the relief assistance for the African drought-affected countries from 1984 to date, has provided relief and medical care services to the Afghan Mujahedeen, and it has assisted a number of countries exposed to disasters. The acquisition of experience in international relief programs has been very helpful to the Saudi Red Crescent Society.

\section{National Policy on Injury Control and Emergency Medical Services (Nige- ria)}

\section{F.A.O. Orosina $M D$}

Lagos, Nigeria

The greatest challenge for Africa in the decade of 1991-2000 is the adoption and implementation by each country of a National Policy on Injury Control, Disaster Reduction, and Community-Oriented Emergency Health Care Services. For example, Nigeria covers an area of 913,072.62 sq. km, has an estimated population of over 100 million with an annual growth rate of $3.12 \%$, a labor force (age 15-50) of $46 \%(80 \%$ are rural dwellers and $80 \%$ of its city dwellers occupy high-density ghettoes). It is a federal Republic consisting of 21 States, a Federal Territory, and 304 Local Government Areas. The Local Government Councils and State Governments have the responsibility for the provision of Health Services supported from funds generated locally and funds allocated by the Federal Government.

The annual rate of increased food production of $1 \%$ cannot match the $3.5 \%$ annual growth rate of food demand. The main source of Federal revenue accrues from the exportation of oil. The revenue obtained does not match the national importation bills which result from trade imbalance and depletion of the foreign Currency Reserve.

Though the recently introduced Structural Adjustment Programme gave a ray of hope, it has not succeeded resuscitating the collapsing economy. Health funding is decreasing progressively and as a result, health care delivery is decreasing in quality and is not available to over $50 \%$ of the population.

Currently, sudden, life-threatening illnesses and injuries are the most common cause for medical consultation. These include: a) injuries from domestic, industry, sports accidents, etc.; and b) assualtive violence by armed robbers or assassins. These causes rank second only to communicable diseases and soon, with improved and more highly successful Primary Healthcare Expanded Programme on Immunization etc., will rank foremost as causes of death in Nigeria. Traumatic injuries already rank highest as the cause of death in persons whose ages are less than 50 years and are the greatest cause of loss of working years and potential years of life loss.

Hand, head, and neck injuries with tendon, brain, spinal cord, and nerve damage are the greatest causes of severe, permanent disablement, loss of earning capacity, disruption of family life, dependency, and economic drain. Children, adult, and elderly women are at greatest risk. Thermal injuries resulting in death, disablement, or disfigurement form another special group to which children and young people are exposed in domestic and industrial environments. Also, disasters of varying magnitude occur more frequently (e.g. derailment of trains, collisions of passenger buses, collapse of high-rise buildings, and fires involving high-rise office buildings and apartment blocks). Population unpreparedness for and panic responses to disasters are responsible for increased morbidity and mortality.

There are no organized emergency medical services in the Country. The social and economic importance of IC and EMS is not recognized by health planners and fund providers. The present government has adopted a National Health Policy which emphasizes Primary Health Care which focuses on rural health and socio-economic development. A National Policy on Injury Control, Disaster Reduction and Emergency Health Care Development is proposed for adoption and implementation in the pursuit of the goal of health for all by the year 2000 . These safety programs should be presented as cardinal Health preventative and promotive concepts to be supported by the government with political will and adequate funding from National Resources and possible assistance from external aids, loans, and grants.

\footnotetext{
Prehospital and Disaster Medicine
}

The population in each community should be convinced to accept the programs as issues for individual and group concern. They should be motivated to become advocates of their own safety and therefore be willing partners of the government in finding solutions and in implementing the programs.

The policy principles and the programs therefore are designed to be community oriented and therefore will to be integrated into the primary health care and community-based Rehabilitation Programs of the Nation. It should be possible foundation for a community-oriented IC and EMS Policy Programme within the local and state governments, and federal government structure and to solicit additional financial support for them from the NGO, UN Agencies, and Industrial and Commercial Organizations. The proposed Health Insurance Scheme should cover a substantial aspect of the EMS Programme.

The objectives, targets, time plan of action, linkage projects, health information systems for research, records, public awareness programs, health, and non-health manpower development projects for the programs are postulated and guidelines for their operation are to be outlined.

\section{Emergency Health Care Development (Japan)}

\section{Takashi Ukai MD}

Osaka Prefectural Senri Critical Care Medical Center, Osaka, Japan

With the development of industry and motorization in the decade of 1960 , road traffic casualties have increased quite rapidly. In response to this social problem, ambulance services were reassigned to the fire departments of each local government. Then, as defined by an Ordinance in 1964, a designated emergency hospital system was developed thus forming a minimal emergency health care system. The target populations for this system were road traffic accident victims. However, in the $1970 \mathrm{~s}$, as the demand for care increased progressively and the designated emergency hospitals were relatively small, the hospitals found that they no longer could meet the quantity and quality of emergency medical services that the public demanded. Since 1978, a new emergency medical services system has been developed in which emergency medical facilities are classified into three groups: primary; secondary; and tertiary. In this new system, coordination of the different levels of medical facilities and the transfer of patients to the most appropriate hospital is recommended. The current status and the problems of this new system will be discussed.

The Rise and Fall of EMS Innovation: A Cautionary Tale from the Dominican Republic

Amiro Perez Mera, MD, Eavid Eaton, PhD

Lyndon B. Johnson School of Public Affairs, The University of Texas at Austin, Austin, Texas, USA

In 1983, the Ministry of Health for the Dominican Republic began planning an

emergency medical service (EMS) system for the capital city of Santo Domingo. The program was based upon careful prior thought regarding the components of an EMS program for a developing country, including considerations regarding the type of EMS care to be delivered, by whom, by what types of equipment, and sited at care system quite different from the uncoordinated mix of public, private, and voluntary services which had operated previously. The program achieved substantial success during its first three years of operations. Following a change in government in 1987, the system was changed substantially. This presentation will consider the development, implementation, and modifications of the system during the period from 1983 to 1987 . It documents the potential for and limits to success in EMS innovation under developing country conditions.

\section{Prehospital Emergency Care in Indonesia: Concepts and Problems}

Ariono D. Pusponegoro $M D$

University of Indonesia School of Medicine, Jakarta, Indonesia

Indonesia is the fifth most populous country of the World. It is comprised of more than 6,000 populated islands with densely populated cities and very isolated rural areas. As a consequence of its geography and stage of development, most of the people live great distances from the nearest health center or hospital, and very few facilities have the capacity to handle serious injuries and other emergencies. Injuries are the third leading cause of death in Indonesia and traffic accidents are responsible for more than $25 \%$ of the fatal injuries. Other major causes of fatal injuries include poisonings, drownings, assault, and disaster-related insults. In an effort to 
improve survival of injury victims with a low-cost practical and effective technology, the Indonesian Surgical Association has established prehospital, telephone-based, emergency medical systems (EMS) in five cities and surrounding areas on the three most populated islands. Each system uses the 118 phone number to receive reports of patients needing assistance and responds by taking the medical facilities to the patients in the form of ambulances and/or field hospitals with a crew consisting of male nurses or paramedical personnel trained in emergency or critical care medicine. Emergency care is directed at controlling failure of the CNS, respiratory, and cardiovascular systems. Supervision is maintained by radio communications and the procedures, services, and training provided by each system vary with the local conditions and resources. Examples of achievements include timely and effective establishment of triage, treatment, and transportation during several recent large-scale disasters (eg train wreck; food poisoning outbreak; explosion of a munitions facility) as well as more than 5,000 ambulances responses per year in Jakarta alone. Weaknesses include limitations on the number of ambulances and financial support. Plans for further development include the establishment of an EMS network in a step-by-step fashion.

\section{Guidelines for Hospital Emergency Units in Ontario}

Ministry of Health for the Province of Ontario, Canada

These guidelines have been developed by the Ministry of Health in order

assist hospital boards in ensuring that hospital emergency units are capable of providing rapid assessment and basic stabilization of patients with life, limb, or function threatening conditions and, when necessary, orgainizing rapid transfers to other treatment facilties.

Part A provides the guidelines to hospital boards in the establishment of policies and practices that will ensure that the emergency unit will be operational and accessible to the public at all times. It addresses: 1) patient admission, discharge, and bed management; 2) attending medical staff responsibilities; 3) delegated medicare procedures; 4) ambulance access; and 5) disaster planning.

Part $B$ delineates the basic operational requirements of the emergecy unit. Its is intended to ensure that the unit will be capable of providing prompt and effective care to the emergency patient. It includes guidelines for: 1) access; 2) administration; 3) patient care; 4) staffing; 5) unit policies; 6) equipment and supplies; 7) pharmacologic interventions; 8) clinical laboratory and diagnostic imaging services; 9) data collection; 10) patient transfer; 11) quality assurance programs; and 12) essential information.

\section{CLINICAL}

\section{Emergency Medical Care in a Senior-Laden Society}

Takahisa Kawashima MD, Takashi Ukai MD, Muneo Ohta MD

Osaka Prefectural Senri Critical Care Medical Center, Osaka, Japan

The number of aged people has been increasing more rapidly in Japan than in any other country. Furthermore, we expect this trend to continue. In view of this phenomenon, in order to better understand the emergency health care problems of senior citizens, we undertook a study over the past nine years. We analyzed data from 1,065 elderly patients brought to the Senri Critical Care Medical Center.

There is/are:

1) an increase of elderly persons over 80 years of age in the lifesaving emergency medical center

2) an increase of elderly DOA patients

3) a change in the disease pattern
4) variant secondary disorders and complications

5) prolongation of hospitalization

6) a burden on society incurred by the expenses generated.

The results of this study point to the necessity of giving furthe consideration to the special problems of elderly emergency patients anc the need to research the effectiveness of limitation of treatment, the role $o$ home doctors, the use of Newmedia for early dissemination of information the use of a rehabilitation system with early physical exercise and coopera tion of referential facilities, and the concept of emergency care based or the patients will to live; and provision of care to achieve satisfactory qualit of life based on each individuals capacity and potential.

\subsection{0 .2}

Behavioral and Psychiatric Aspects and Consequences of the Armeniar Earthquake

Professor Marat Vartanian, MD

Director, All-Union Mental Health Research Centre, Moscow, USSR

This presentation centers on the basic behavioral characteristics of thepopu lations that suffered in the Armenian Earthquake of December 1988 Short-term and long-term effects in children, middle-aged, and elderly people are considered. Medical assistance to these population group: ranged from psychotropic medication to group therapy methods. A total of 12,000 people were examined by psychiaytrists and psychologist in the earthquake area. Their attention concentrated on the high-risk groups: 1) crush-syndrome; 2) people rescued from the ruins in the earthquake area: 3) people who lost their families; 4) children and adolescents; and 5) the elderly. A system of step-by-step psychological and psychiatric care to the victims and their families was used. A branch of the All-Union Mental Health Research Centre, USSR Academy of Medical Sciences was put into operation in Armenia.

The organizational principles of these services and long-term rehabilitation for victims are presented. The prospects for international collaborations in the field are analyzed.

\section{Burn Therapy Studies in Turkey}

Mehmet Haberal MD, FACS

Hacettep University Hospitals and the Turkish Transportation and Burn Foundation Hospital, Ankara, Turkey

Burn therapy has long been a major problem in Turkey. The therapy of electrical burns is of great importance. In our Country, electrical energy is used widely but sometimes inappropriately. For this reason, the incidence of this type of injury which causes severe complications and death is quite high. It is a common occurence that an average $15 \%$ of the patients admitted to our burn unit have been diagnosed as having electrical burns. Studies relative to burn therapy in our country started in 1975. The first burn unit was establisherd by our team in Ankara Gulhane Military Hospital. Subsequently, a 15-bed burn unit was established by our team in the Ankara Hacettepe University Hospital. Many other units have joined us in our studies relative to the prevention and therapy of burns. Currently, six hospitals in different cities have special burn units and in 107 hospitals burn therapy is being carried on though there are no special burn units in their departmental structures. Altogether, we tried to introduce safety measures through a systematic approach to society. Also, through review of the literature and the use of case-controlled studies, we are trying to improve the therapy used for burns. Furthermore, following the establishment of the Turkish Transportation and Burn Foundation in September 1980, the scope of these studies increased greatly. Through international studies and conferencing, we have been able to describe our relevant activities and studies to other countries and we have been able to incorporate the newest relevant findings in the World into our methods. 


\section{We're making waves in emergency medicine.}

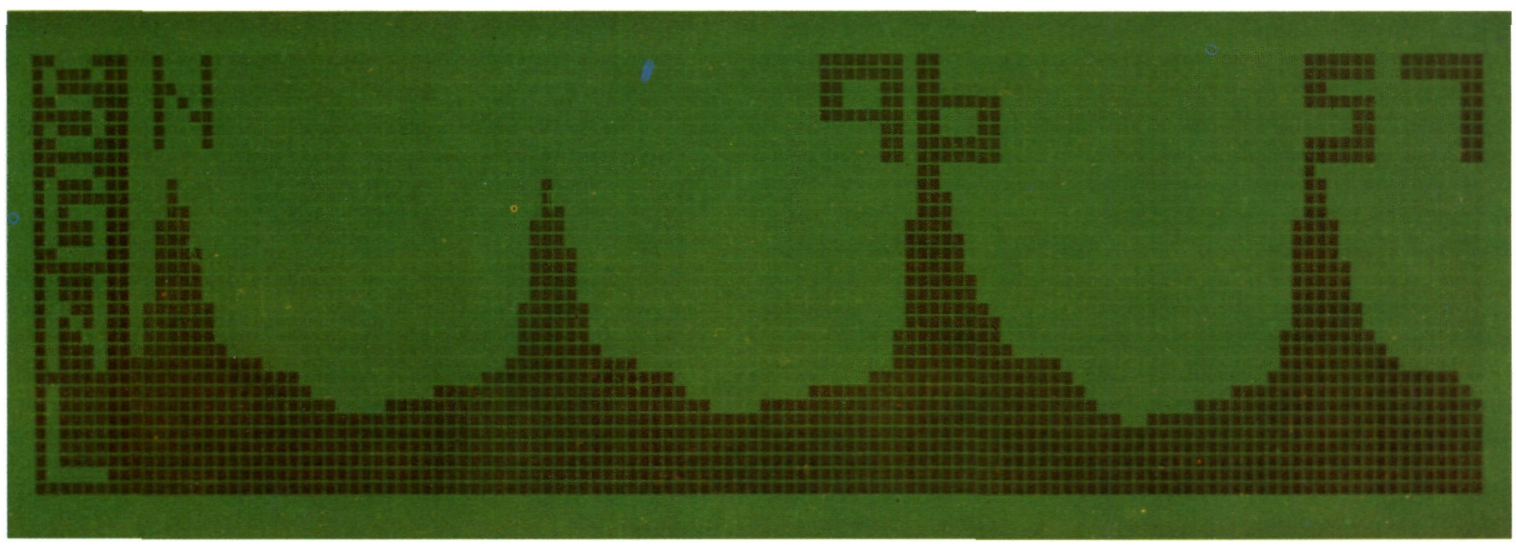

“...pulse oximetry provides a rapid and accurate assessment of oxygen saturation in both the ambulance and helicopter..." 1 John Galdun, M.D. Emergency Medicine

Today, pulse oximetry is the big news in pre-hospital and emergency room care. Because only pulse oximetry offers a noninvasive way to monitor arterial oxygen saturation before, during and after transport. It's instantaneous feedback that can help you obtain a more complete picture of your patient's status.

And of all the pulse oximeters out there, none can do the job more effectively than the Ohmeda Biox 3740. Not because of its small size, or ease of use, or even its battery power. But because the 3740 features a unique waveform display that helps you overcome potential interference problems and obtain accurate readings.
How important is waveform? “...pulse oximetry without a waveform does not provide the necessary clinical information to make informed decisions on oxygenation:" Michael Yaron, M.D. Emergency Department University Hospital University of Colorado

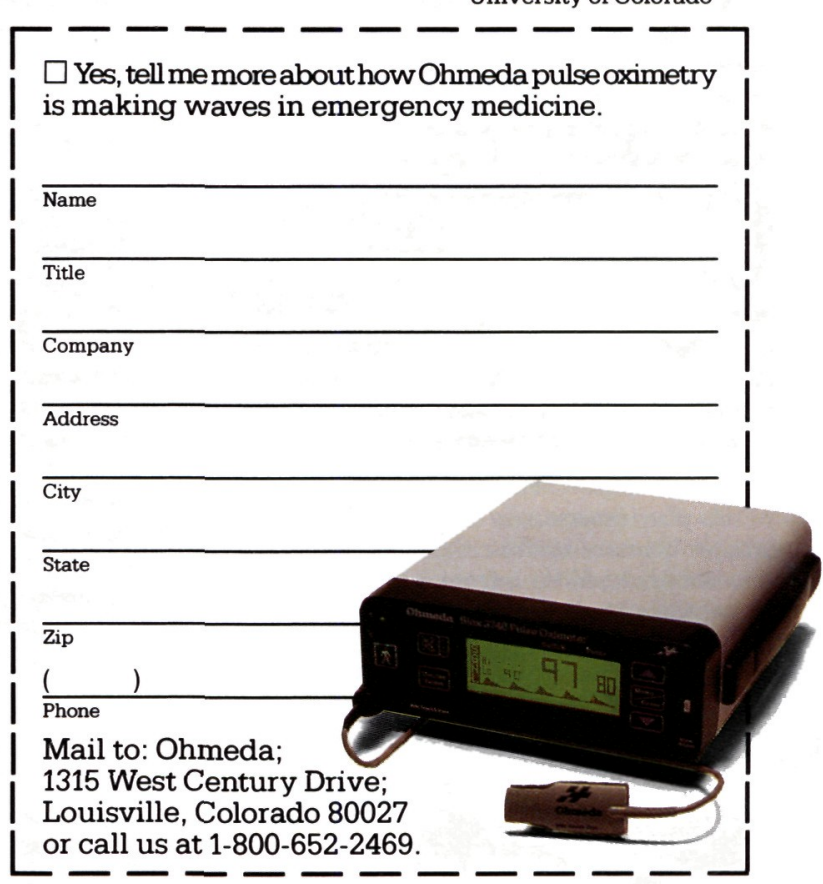

\section{Ohmeda}

